\title{
Long-Lasting Antiandrogen Withdrawal Syndrome in Castration-Resistant Prostate Cancer: Three Cases With Complete Response
}

\author{
Sang Jin Kim, Jae Hyun Ryu, Yun Beom Kim, Tae Young Jung \\ Department of Urology, Veterans Health Service Medical Center, Seoul, Korea
}

This is a case report of 3 patients who had a dramatic and long-term complete response after antiandrogen withdrawal. All 3 patients were diagnosed with advanced or metastatic prostate cancer with a high prostate-specific antigen (PSA) level. For all patients, we started combined androgen blockade as androgen deprivation therapy and the PSA concentration decreased to $<0.1 \mathrm{ng} / \mathrm{mL}$, but then started to increase. After discontinuation of antiandrogen the PSA concentration decreased again and has remained below the limit of sensitivity for more than 1 year in all 3 patients. (Korean J Urol Oncol 2018;16:38-41)

Key Words: Androgen antagonists - Androgen deprivation therapy - Antiandrogen withdrawal syndrome Castration resistant prostatic neoplasms $\cdot$ Complete response

Antiandrogen withdrawal syndrome (AWS) is defined as subjective and/or objective improvement after the discontinuation of antiandrogen during combined androgen blockade (CAB) therapy. AWS in prostate cancer (PC) was observed in all type of antiandrogens. ${ }^{1-3}$

Generally, a prostate-specific antigen (PSA) response is reported in $15 \%$ to $30 \%$ patients and the duration of response is limited to several months, with a median of 4 months. ${ }^{4}$ In the present report, we describe 3 patients who showed complete withdrawal response for more than 1 year after antiandrogen withdrawal.

Received March 23, 2018, Revised March 23, 2018,

Accepted April 4, 2018

Corresponding Author: Tae Young Jung

Department of Urology, Veterans Health Service Medical Center, 53 Jinhwangdo-ro 61-gil, Gangdong-gu, Seoul 05368, Korea

E-mail: urodoct@hotmail.com

Tel: +82-2-2225-1739, Fax: +82-2-2225-4374

ORCID code: https://orcid.org/0000-0002-4634-3370

\section{CASE REPORTS}

\section{Case 1}

A 72-year-old man visited Veterans Health Service Medical Center on March 2012 due to elevation of PSA level, which was $29.52 \mathrm{ng} / \mathrm{mL}$. Prostate biopsy revealed adenocarcinoma with a Gleason score (GS) of $3+3=6$. There was no bone metastasis or lymphadenopathy on imaging study but magnetic resonance imaging showed perineal invasion of PC. CAB consisting of goserelin and bicalutamide $50 \mathrm{mg}$ was started. The PSA concentration significantly decreased within 3 months and reached a nadir of $<0.01 \mathrm{ng} / \mathrm{mL}$ by November 2012 .

The PSA concentration started increasing gradually from February 2013, and reached $13.93 \mathrm{ng} / \mathrm{mL}$ by October 2014. The testosterone concentration was identified at the castration level. Bicalutamide was discontinued to confirm AWS. The PSA concentration started to decline again, and dropped to $<0.01$ $\mathrm{ng} / \mathrm{mL}$ within 6 months. There was a new metastatic bone lesion in the right pubic bone on follow-up computed tomography (CT) and bone scan performed in February 2015.

cc) (i) (\$) This is an Open Access article distributed under the terms of the Creative Commons Attribution Non-Commercial License (http://creativecommons.org/licenses/by-nc/4.0/) which permits unrestricted non-commercial use, distribution, and reproduction in any medium, provided the original work is properly cited. 2018 (C) Copyright The Korean Urological Oncology Society and The Korean Prostate Society. All Rights Reserved. 
However, a CT scan on September 2015 indicated disappearance of the lesion during discontinuation of antiandrogen (Fig. 1). The PSA concentration has been maintained below the limit of sensitivity up to the time of writing, which is over 3 years (Fig. 2A).

\section{Case 2}

A 61-year-old man was diagnosed with PC, which was ad-
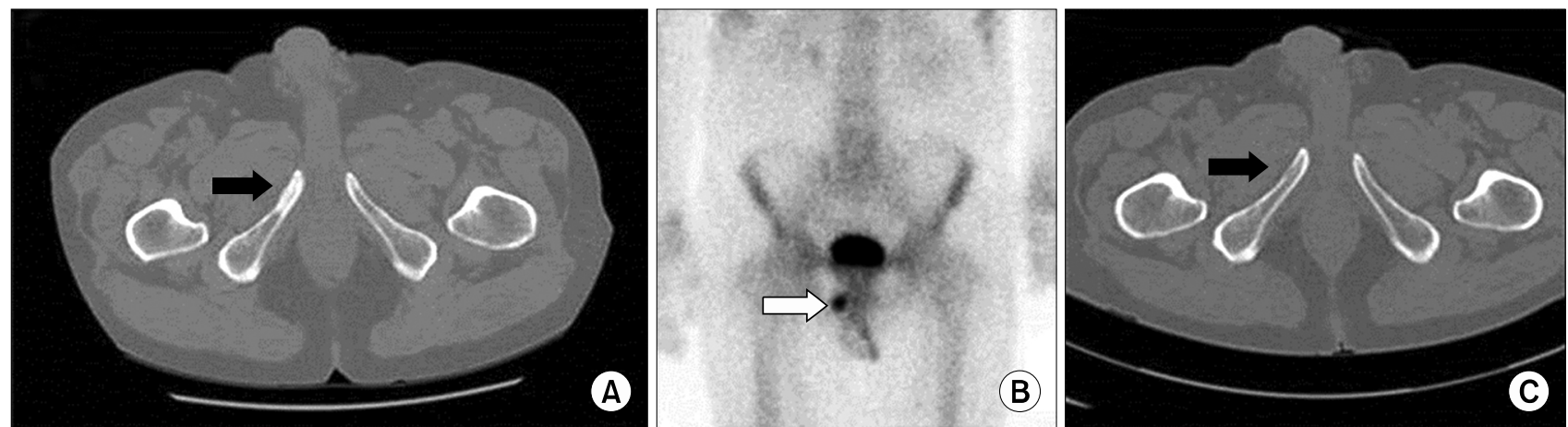

Fig. 1. Imaging study of patient 1 during antiandrogen withdrawal. (A, B) Computed tomography (CT) and bone scan taken February 2015. Sclerotic bone lesion on CT (black arrow) and increased radiouptake on bone scan (white arrow) were noted in right pubic bone, suggesting metastasis. (C) CT taken September 2015. The sclerotic bone lesion disappeared during antiandrogen withdrawal (black arrow).
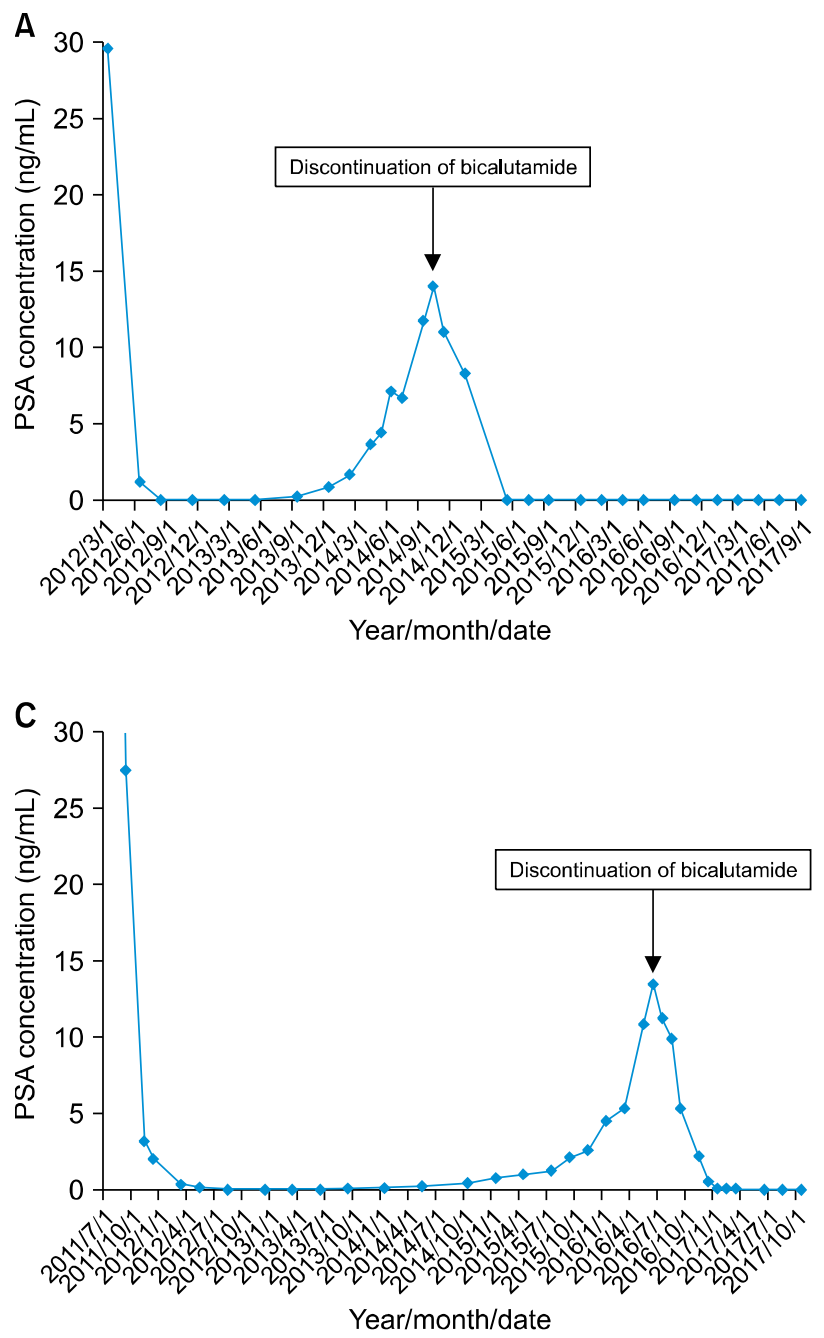

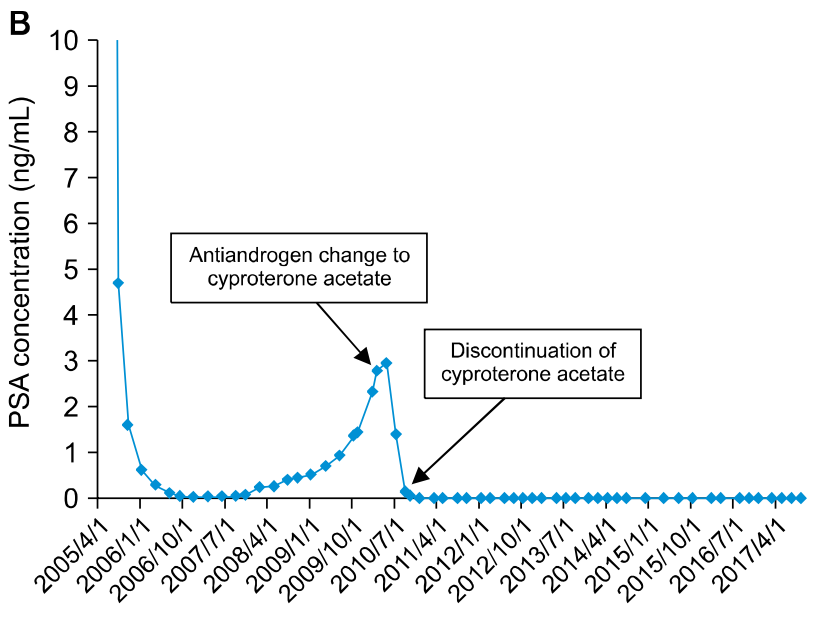

Year/month/date
Fig. 2. Change in serum prostate-specific antigen (PSA) concentration in case $1(\mathrm{~A})$, case $2(\mathrm{~B})$, and case $3(\mathrm{C})$. 
enocarcinoma with GS $4+4=8$, in April 2005. The initial PSA concentration was $4,420 \mathrm{ng} / \mathrm{mL}$, and imaging study demonstrated multiple bone metastases, lymph node metastasis, and bladder invasion of PC. CAB consisting of goserelin and bicalutamide $50 \mathrm{mg}$ was started. After 1 month, the PSA concentration had sharply decreased to $74.39 \mathrm{ng} / \mathrm{mL}$, and reached a nadir of $0.02 \mathrm{ng} / \mathrm{mL}$ in March 2007, 23 months after the treatment. Thereafter, the PSA concentration started to increase and reached $2.76 \mathrm{ng} / \mathrm{mL}$ in March 2010. The testosterone concentration was identified at the castration level. For the secondary antiandrogen therapy, bicalutamide was changed to the steroidal antiandrogen cyproterone acetate (CPA) $200 \mathrm{mg}$ daily. The PSA concentration decreased again after a month and reached $0.14 \mathrm{ng} / \mathrm{mL}$ within 6 months after the administration of CPA, in September 2010.

In September 2010, the patient was hospitalized in the Department of Internal Medicine due to jaundice. His alanine aminotransaminase/aspartate aminotransferase level was elevated to $764 / 533 \mathrm{U} / \mathrm{L}$ and total bilirubin was elevated to 9.8 $\mathrm{mg} / \mathrm{dL}$. He had been taking herbal medicines every day for the previous 3 months. Under an impression of drug-induced hepatitis, all medicines including CPA were discontinued. CT scan showed no structural abnormality of liver and bile duct; furthermore, pelvic lymphadenopathy and metastatic bone lesion were not detected. After conservative treatment for 1 month, the patient was discharged.

The patient continued with discontinuation of CPA, and the PSA concentration decreased further to $0.05 \mathrm{ng} / \mathrm{mL}$ in October 2010. Since then, the PSA value decreased gradually to an undetectable level, and has remained $<0.02 \mathrm{ng} / \mathrm{mL}$ to date, which is over 7 years (Fig. 2B).

\section{Case 3}

A 64-year-old man was diagnosed with PC, which was adenocarcinoma with GS of $4+4=8$, on August 2011. The initial PSA concentration was $185 \mathrm{ng} / \mathrm{mL}$ and bone scan showed no bone metastasis. CT scan showed surrounding fat involvement of PC with no direct invasion of adjacent organs, and enhancing areas in the surface area of the liver segment 8 , which was suspected metastasis.

$\mathrm{CAB}$ with triptorelin acetate and bicalutamide $50 \mathrm{mg}$ was started. The PSA concentration decreased to $3.13 \mathrm{ng} / \mathrm{mL}$ within 3 months and reached a nadir of $<0.01 \mathrm{ng} / \mathrm{mL}$ by December 2012. Metastatic lesion of liver had disappeared on a CT scan performed in December 2011. The PSA concentration remained at a nadir level for 6 months, but started to increase from June 2013 and reached $13.46 \mathrm{ng} / \mathrm{mL}$ on June 2016. The testosterone concentration was identified at the castration level and the follow-up CT and bone scan showed no progression of PC. Bicalutamide administration was discontinued from June 2016. The PSA concentration gradually decreased and has remained $<0.01 \mathrm{ng} / \mathrm{mL}$ to date, which is 1.5 years (Fig. 2C).

\section{DISCUSSION}

AWS is a well-known phenomenon during hormone therapy of PC, and a relationship between AWS and changes in PSA level is observed for all types of antiandrogens. The best-supported molecular mechanism explaining AWS is mutation of the androgen receptor gene in castration-resistant prostate cancer (CRPC) that causes the antiandrogen to behave as an androgen agonist. ${ }^{5,6}$

Although the general duration of AWS is limited to several months, it has been reported to last for more than a year. Hongo et al. $^{7}$ reported a prolonged complete withdrawal response for almost 2 years in a patient with metastatic PC. Also, Sano et al. $^{8}$ reported a patient who achieved complete response with a duration of more than 6 years. In our three case reports the response duration was very long $(3,7$, and 1.5 years, respectively), and all patients showed complete response (PSA level $<0.01-0.02 \mathrm{ng} / \mathrm{mL}$ ). Furthermore, in patient 1 , the patient showed radiologic improvement after antiandrogen withdrawal. Because there was no CT image for just before antiandrogen withdrawal, it was somewhat difficult to determine whether AWS was the direct cause of the radiologic response. However, the continued lack of metastatic disease in subsequent imaging surveillance following antiandrogen interruption was considered a positive response to antiandrogen withdrawal.

In 2008 Sartor et al. ${ }^{9}$ analyzed factors that affect the AWS. They reported that the duration of prior antiandrogen therapy was a significant predictor of PSA response. Especially, patients who received antiandrogen therapy $>32$ months prior to withdrawal showed a greater than $50 \%$ reduction in the risk for progression-free and overall survival. More than 24 months of prior antiandrogen therapy was noted in these three cases.

It is unclear whether a good response to antiandrogen withdrawal represents a better prognosis. Antiandrogen withdrawal is not included in the 2017 European Association of Urology- 
European Society for Radiotherapy \& Oncology-International Society of Geriatric Oncology guidelines for CRPC treatment. ${ }^{10}$ Instead, docetaxel-based chemotherapy is accepted as the primary treatment even though it often has strong adverse effects. Through antiandrogen withdrawal, we were able to prevent cancer progression without any side effects in our 3 patients with advanced PC. Antiandrogen withdrawal is a favorable approach for refractory disease in terms of quality of life for the patients.

The role of antiandrogen withdrawal, which was the usual treatment for CRPC in the past, is now decreasing due to the emergence of new drugs. However, in some patients a complete PSA response, and even a radiologic response, is observed following antiandrogen withdrawal. In addition, antiandrogen withdrawal has the advantage of reducing the side effects caused by drugs. In conclusion, antiandrogen withdrawal should be considered during the treatment process, not only for the therapeutic effect but also for improved quality of life of patients with CRPC. It is necessary to refocus on simple and safe treatment strategies such as antiandrogen withdrawal, and further studies should be conducted for effective use of this therapy.

\section{CONFLICT OF INTEREST}

The authors claim no conflicts of interest.

\section{REFERENCES}

1. Kelly WK, Scher HI. Prostate specific antigen decline after antiandrogen withdrawal: the flutamide withdrawal syndrome. J Urol 1993;149:607-9.

2. Small EJ, Carroll PR. Prostate-specific antigen decline after casodex withdrawal: evidence for an antiandrogen withdrawal syndrome. Urology 1994;43:408-10.

3. Kelly WK, Slovin S, Scher HI. Steroid hormone withdrawal syndromes. Pathophysiology and clinical significance. Urol Clin North Am 1997;24:421-31.

4. Kim SJ, Kim SI. Current treatment strategies for castration-resistant prostate cancer. Korean J Urol 2011;52:157-65.

5. Taplin ME, Bubley GJ, Shuster TD, Frantz ME, Spooner AE, Ogata GK, et al. Mutation of the androgen-receptor gene in metastatic androgen-independent prostate cancer. N Engl J Med 1995;332:1393-8.

6. Taplin ME, Bubley GJ, Ko YJ, Small EJ, Upton M, Rajeshkumar B, et al. Selection for androgen receptor mutations in prostate cancers treated with androgen antagonist. Cancer Res 1999;59:2511-5.

7. Hongo H, Kosaka T, Oya M. Complete response to bicalutamide withdrawal prolonged for almost 2 years in patients with metastatic prostate cancer. Urol Case Rep 2014;2:150-1.

8. Sano M, Yamamoto S, Uehara S, Yuasa T, Masuda H, Fukui I, et al. Long-term complete response of antiandrogen withdrawal syndrome in a patient with metastatic prostate cancer: A case report. Mol Clin Oncol 2016;5:208-10.

9. Sartor AO, Tangen CM, Hussain MH, Eisenberger MA, Parab M, Fontana JA, et al. Antiandrogen withdrawal in castrate-refractory prostate cancer: a Southwest Oncology Group trial (SWOG 9426). Cancer 2008;112:2393-400.

10. Cornford P, Bellmunt J, Bolla M, Briers E, De Santis M, Gross T, et al. EAU-ESTRO-SIOG guidelines on prostate cancer. Part II: treatment of relapsing, metastatic, and castration-resistant prostate cancer. Eur Urol 2017;71:630-42. 